
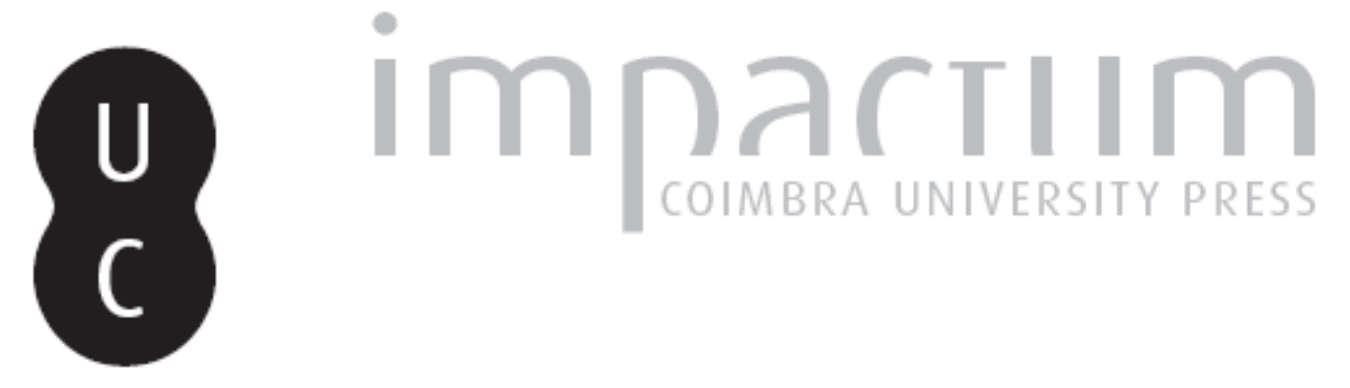

\title{
Problemas em aberto na epigrafia mirobrigense
}

Autor(es): D'Encarnação, José

Publicado por: Imprensa da Universidade de Coimbra

URL persistente:

URI:http://hdl.handle.net/10316.2/45445

DOI:

DOI:https://dx.doi.org/10.14195/1647-8657_35_6

Accessed : $\quad$ 26-Apr-2023 13:43:56

A navegação consulta e descarregamento dos títulos inseridos nas Bibliotecas Digitais UC Digitalis, UC Pombalina e UC Impactum, pressupõem a aceitação plena e sem reservas dos Termos e Condições de Uso destas Bibliotecas Digitais, disponíveis em https://digitalis.uc.pt/pt-pt/termos.

Conforme exposto nos referidos Termos e Condições de Uso, o descarregamento de títulos de acesso restrito requer uma licença válida de autorização devendo o utilizador aceder ao(s) documento(s) a partir de um endereço de IP da instituição detentora da supramencionada licença.

Ao utilizador é apenas permitido o descarregamento para uso pessoal, pelo que o emprego do(s) título(s) descarregado(s) para outro fim, designadamente comercial, carece de autorização do respetivo autor ou editor da obra.

Na medida em que todas as obras da UC Digitalis se encontram protegidas pelo Código do Direito de Autor e Direitos Conexos e demais legislação aplicável, toda a cópia, parcial ou total, deste documento, nos casos em que é legalmente admitida, deverá conter ou fazer-se acompanhar por este aviso.

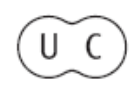


UNIVERSIDADE DE COIMBRA

FACULDADE DE LETRAS

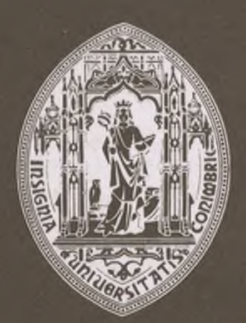

\section{CONIMBRIGA}

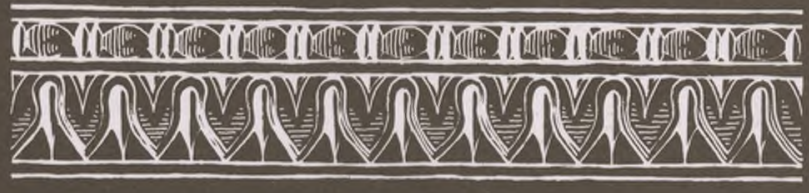

VOLUME XXXV - 1996 
JoSÉ D’ENCARNAÇÂO

Professor da Faculdade de Letras de Coimbra

\section{PROBLEMAS EM ABERTO NA EPIGRAFIA MIROBRIGENSE}

"Conimbriga" XXXV (1996) p. 129-146

RESUMO: Retoma-se a problemática que ainda envolve a epigrafia da cidade

romana habitualmente identificada como Miróbriga dos Célticos, sita junto a Santiago do Cacém e que, na Antiguidade, estava no território do conventus Pacensis. Reflecte-se sobre o estatuto dessa cidade e, inclusive, sobre a sua identificação; referem-se as famílias aí influentes na época romana; salienta-se o interesse historiográfico que detém a existência de cópias de inscrições; e, depois de algumas reflexões sobre a importante ara dedicada a Esculápio (CIL II 21), apontam-se novas leituras para três epígrafes.

RESUMÉ: On reprend la problématique de Tépigraphie romaine de Mirobriga,

une ville du conventus Pacensis qu'on identifie avec les vestiges fouillés à côté de Factuelle Santiago do Cacém, dans le Sud du Portugal. Quels étaient vraiment son nom et son statut juridique? Et les familles y dominantes? CIL II 21 - une importante dédicace à Esculape - et d'autres trois inscriptions sont aussi objet d'analyse. L'intérêt, du point de vue historiographique, de l'existence de copies modernes d'inscriptions romaines disparues est mis en évidence. 
(Página deixada propositadamente em branco) 


\section{PROBLEMAS EM ABERTO NA EPIGRAFIA MIROBRIGENSE *}

A circunstância de a epigrafia de Miróbriga ter sido estudada, no seu conjunto, numa obra que abarcava todo o conventus Pacensis ou seja, grosso modo todo o Sul de Portugal (IRCP, 217-250), poderá contribuir para que alguns dos problemas em aberto passem despercebidos ou não sejam encarados com a devida atenção.

Façamos, pois, breves reflexões a tal respeito.

No cômputo das inscrições procedentes da área das ruínas do chamado «Castelo Velho» e do seu termo 0), deverá ter-se em conta que — sem considerarmos os seis fragmentos da homenagem ao imperador

(*) Parte significativa deste texto chegou a estar em segundas provas, para ser incluída no III volume (2. ${ }^{a}$ série) dos Anais da Real Sociedade Arqueológica Lusitana, de Santiago do Cacém, que teria a data de 1989. Concluíra-a a 8 de Fevereiro de 1991. Como, porém, a carta de 21.8.1996 de José António Falcão - responsável directo pelo reaparecimento dos Anais - me não dava quaisquer garantias de que a iniciativa da publicação fosse por diante, tomei a liberdade de o refundir e dar-lhe outro destino.

0) São, de momento, trinta e uma as epígrafes dadas como oriundas da zona das ruínas. IRCP 152 apareceu, segundo informou D. Fernando de Almeida (1964, 14), em 1957, com muitos materiais romanos, a cerca de quatro quilómetros das ruínas, «em uma propriedade denominada Francisquinho, freguesia de Santa Cruz». IRCP 153 e 173 foram sumariamente noticiadas por Manuel Barreto e dementino Amaro (Barreto 1980), que as assinalam como provenientes da necrópole sita a cerca de 200 metros a nordeste da villa de Conqueiros, freguesia de Alvalade-Sado: encontraram-se casualmente, durante os trabalhos agrícolas. Já foi possível obter fotografias destes monumentos e saber do seu actual paradeiro, pelo que ora se apresenta o seu estudo mais documentado. Os mesmos arqueólogos informam da existência de uma segunda villa na mesma freguesia, na herdade da Corona; mas a ara romana a que se alude no resumo da comunicação distribuído aos congressistas não parece ter provindo desta herdade, como a princípio supus (IRCP, 217), mas sim do adro da igreja da freguesia, onde foi achada no decorrer das obras aí realizadas.

Conimbriga, 35 (1996) 129-146 
Aureliano - há nada menos que dezassete pequenos fragmentos de que nenhuma informação histórica se pode deduzir. No fundo, portanto, não é muita epigrafia para uma cidade, ao contrário do que à primeira vista poderia parecer.

São quatro as inscrições votivas a divindades do panteão clássico: Esculápio, Marte e Vénus (2).

Dois textos poderão incluir-se no número das homenagens imperiais:

- IRCP 148 é minúsculo fragmento somente conhecido através de inexpressivo desenho de Frei Manuel do Cenáculo, onde Hübner tentou ver, hipoteticamente, parte da identificação do imperador Trajano;

- o outro, retalhado em diversos fragmentos escritos dum lado e doutro, considerei-o passível de reconstituir como dedicatória da cidade ao imperador Aureliano (IRCP 149, Encarnação 1984-88).

Há duas inscrições honoríficas (IRCP 150 e 151) e apenas sete textos funerários detêm algum significado para o conhecinento da onomástica local.

Daí resulta, por exemplo, que o estatuto e o próprio nome da cidade não estejam epigraficamente documentados e pouco se saiba também das famílias aí influentes.

Do ponto de vista epigráfico, a existência de cópias merece igualmente alguma reflexão e o texto a Esculápio ainda suscita controvérsia.

Finalmente, maior atenção às paredes das casas que se remodelarem no perímetro urbano de Santiago do Cacém (decerto para a sua construção foi carreada muita pedra do «castelo»...); a releitura de manuscritos; e mais intensa prospecção pelos arredores (designadamente onde houver villae) e, mesmo, no aro de Sines (onde foram identificados novos monumentos epigráficos, a publicar, em breve, no Ficheiro Epigráfico) - proporcionariam, sem dúvida, outros achados, como aquele de que se deu notícia em 1988 (cf. Falcão et alii) e sobre o qual também gostaria de tecer algumas considerações.

(²) Cf. ENCARNAÇão 1981, 27, e IRCP 144-147. 


\section{Mirobriga? E que estatuto?}

Fábio Isas eternizou em notável ara de calcário a benemerência do médico pacense Gaio Átio Januário, de quem fora nomeado herdeiro (IRCP 144). Já voltarei daqui a pouco a esta importante epígrafe; por ora, ela interessa-nos apenas porque aí se alude aos méritos "da muito esplêndida ordem", merita splendidissimi ordinis. Ordo era, na linguagem oficial das cidades romanas, a "ordem dos decuriões", o que hoje poderíamos chamar de "conselho municipal". Desta referência se deduziria, pois, que existia no local um município.

Traz Frei Manuel do Cenáculo, entre os desenhos do seu álbum (pasta CXXIX/ 1-13), um que representa como sendo a parte superior dum rectángulo ao alto, gasto na zona inferior direita. Teria, segundo diz, «3 palmos de largo» (ou seja, no sentido longitudinal) e «3 */2 palmos de comprido» (ou seja, de altura). O desenho vem repetido na f. 7 da p. LXV, a que se segue, na f. 8, um outro fragmento que parece ser justamente o canto inferior direito da pedra anterior, não só pelo desenho como também pelo facto de o próprio Frei Manuel do Cenáculo afirmar que é «da mesma qualidade e grossura que a antecedente e a moldura do mesmo feitio». Conhece-se a precisão que o arcebispo de Évora punha nas suas observações e a fidelidade do seu traço; não me repugnou, por isso, ver na pedra, na sequência de Hübner (CIL II 25), a homenagem a Marco Júlio Marcelo, edil e duúnviro (IRCP 150).

$\mathrm{Na}$ linha 4 desse texto, surgem as siglas M. F. a preceder o $\mathrm{M}$ inicial dum outro vocábulo cujas letras desepareceram na fractura e que Hübner reconstituiu dubitativamente como Merobrig(ensis). A hipótese M(unicipii) F(lavii) Mirobrig(ensis) é, pois, aliciante (cf. Alarcão 1990, 364). Teríamos assim: primeiro, a confirmação do estatuto municipal outorgado a Mirobriga; segundo, a indicação, assaz preciosa, de que fora elevada a município ao tempo dos Flávios (segunda metade do século I da nossa era); e, finalmente, por esses dados virem em sigla, a informação - complementar mas sintomática — de que tal estatuto era sobejamente conhecido.

Achados em 1801 e 1808, respectivamente, os dois fragmentos levaram sumiço. Reencontrá-los seria, na verdade, importante achega para a solução dum problema que, doutra sorte, continuará na esfera das hipóteses, uma vez que nada nos garante, por enquanto, o referido desdobramento dessas siglas. 
Mas também o nome já tradicionalmente atribuído à povoação que, ao tempo dos Romanos, se ergueu nos terrenos em torno da actual ermida de S. Brás( $\left.{ }^{3}\right)$ não pode admitir-se sem reservas. Pelo menos se atendermos aos dados epigráficos.

Como vimos, apenas um $\mathrm{M}$ figura na inscrição de Marco Júlio Marcelo. Mas há o referido epitáfio achado no «Francisquinho» que memora Gaio Pórcio Severo identificado claramente como mirobrigensis celticus (IRCP 152)!... Já tive ocasião de manifestar a minha grande perplexidade quanto à autenticidade do monumento $\left({ }^{4}\right)$;

\section{1. $\left.{ }^{\circ}\right)$ Do ponto de vista paleogràfico}

a) não é habitual tão grande variedade de pontuação — desde as heras de longo pecíolo em ângulo (esquecido no final da linha 1) ao ponto triangular da linha 2 e aos inusitados triângulos das linhas 4 e 5;

b) o traçado das letras está demasiadamente nítido, o que se admira no mármore sujeito durante séculos à acção corrosiva dos terrenos onde jazia;

c) o nexo EN da linha 3 não está documentado, pelo que me é dado conhecer;

d) na linha 5, o E tem a barra mediana mais curta, o que é, na epigrafia romana peninsular, sintoma claro de não ter sido grafado por lapicida romano (a igualdade das barras era norma rigorosameate respeitada).

\section{2. $\left.{ }^{\circ}\right)$ Do ponto de vista formal}

A molduração não se enquadra nos modelos romanos - e se o analfabetismo podia, por vezes, determinar erros ortográficos, o saber

(3) Sobre as ruínas de Miróbriga, veja-se BIERS 1988 e a recensão dessa obra feita por Jorge de ALARCão («Conimbriga» 281989 243-245), onde também se aflora a problemática do estatuto político-administrativo do sítio. Cfr. ainda: CORREIA 1990 e BARATA 1993.

${ }^{4}$ ) A realização de cuidadosas sondagens no local de proveniência da placa poderá trazer informações complementares. Qual é o seu verdadeiro contexto arqueológico? Uma villa? Uma necrópole? Caso seja necrópole, torna-se verosímil o achamento de mais epitáfios. E seria interessante identificar outros testemunhos da existência duma gens Porcia na região. Não faltam, é certo, no mundo romano, gentes atestadas aqui e ali por uma única inscrição; mas, em toda a Lusitânia, só dois Porcii se registam: L. Porcius Himerus, um notável municipal de Salácia (IRCP 187), e Porcia Materna em Mértola (IRCP 115). 
artesanal dos artífices e o seu desejo de seguir com rigor os modelos clássicos raramente deixa de se observar.

\section{$\left.3^{\circ}\right)$ Do ponto de vista textual}

Não é normal que se indique a naturalidade dum mirobrigense enterrado na sua terra natal. Essa menção é sinal distintivo e só se usa (ainda hoje!) quando alguém está deslocado. Seguindo a lógica deste raciocínio, o epitáfio provaria, sim, que ali não era Mirobriga Celticum ( ${ }^{5}$ )!

Em conclusão: este documento parece ter sido forjado com a intenção de eficazmente corroborar a ideia de que as imponentes ruínas romanas junto a Santiago do Cacém pertenciam a uma importante cidade, eventualmente a capital dos Mirobricenses qui Celtici cognominantur, «mirobrigenses cognominados de célticos», a que se refere o escritor romano Plínio, o Velho, na obra História Natural (IV, 118).

Não se declara - entenda-se - que esta tradição esteja errada. Enquanto válida prova em contrário se não apresentar, não haverá problema em manter a denominação. Mas esteja-se bem ciente de que não há também, ainda, nenhuma fonte epigráfica que a autentique. Falta achar - e decerto haverá uma dedicatória imperial feita oficialmente pela civitas. $\mathrm{Ou}$ a homenagem da cidade a um notável municipal. A presença, no vizinho porto de Sines, de um imponente pedestal a Marte Augusto dedicado por um sacerdote do culto imperial (cf. Encarnação 1992), poderá, no entanto, contribuir para repor a questão do relacionamento institucional entre os dois aglomerados populacionais, ambos deveras importantes na época romana.

\section{As famílias influentes}

A relativa escassez de inscrições impede-nos de traçar um quadro das famílias que dominaram em Mirobriga.

A presença de C. Iulius Rufinus (IRCP 146) e do já referido $M$. Iulius Marcellus (IRCP 150) vai no sentido de que, também aqui, uma gens Iulia, ligada quiçá por laços de favor à família imperial, gozou de 
alguma supremacia: Rufino foi magister, sacerdote $\left(^{6}\right)$ do culto a Vénus, divindade da particular devoção dos Júlios-Cláudios; Marcelo assumiu, como se disse, as funções de edil e de duúnviro, pelo menos.

Próprios desta localidade, embora sem importância política atestada, parecem ter sido os Caii Pagusici documentados em três epígrafes (IRCP 145, 156 e 157). Alguns dos seus membros uniram-se pelo casamento à gens Scribonia (IRCP 157 e 158) - que terá detido alguma importância na localidade — e quiçá igualmente à gens Valeria (IRCP 151 e $160\left({ }^{7}\right)$ ), atendendo ao cognome Valeriano de Gaio Pagùsico $\left.{ }^{8}\right)$ (IRCP 157).

Particular menção nos merecem os Castricii (IRCP 151 e 159). A existência em Évora desta família (Encarnação 1990, 247-251), com muito provável ligação à Bética, onde outros testemunhos se detectaram, veio reforçar o interesse da homenagem aqui prestada a Gaio Atio Rufo ( ${ }^{9}$ ) (indígena que em Itálica foi elevado à categoria de cidadão) por dois dos seus amigos: Marco Casilicio Lucanião e Gaio Valério Pézon $\left({ }^{10}\right)$. O relacionamento dos três núcleos populacionais - Miróbriga, Ebora Liberalitas Mia (Évora) e Italica (Sevilha) - reveste-se, assim, de particular significado. Mas... que tipo de relacionamento seria esse? De cariz económico? De âmbito político-administrativo?

\section{As cópias}

Do ponto de vista da história da cultura e, de modo especial, do ponto de vista da história da Epigrafia, há que realçar a ocorrência, em

$\left(^{6}\right)$ Discutiu-se o significado do vocábulo magister. O achamento da ara de Talaíde, oferecida por dois magistri duma deusa, incita, porém, a dar-lhe, de preferência, uma conotação religiosa (cf. IRCP, 223).

(7) Carmen Castillo $(198,133)$ deu deste texto uma interpretação ligeiramente diferente da que eu apresentei: "[D(is) M(anibus) S(acrum). Valeriae] L. fliliae) / [cerca de 5 letras] ae test(amento) / C. Valeri Vibiani/frat(ris). Curat(or) C. / Valerius Asbestus / lib(ertus), her(es). E, na última linha, se é que a havia, a fórmula p(atronae) o(ptimae)».

${ }^{8}$ ) Sigo a sugestão de Francisco de OLIVEIRA $(1986,342)$ na versão portuguesa deste antropònimo.

( $\left.{ }^{9}\right)$ Cf. AlarCão 1990, 474.

$\left({ }^{10}\right)$ Sigo, também aqui, a sugestão de Francisco de OLIVEIRA (1936, 342): Pézon em vez de Paezão. 
Santiago do Cacém, de cópias de inscrições antigas. Quatro são idênticas, de mármore, e foram encastradas, duas de cada lado, na parede do chafariz de Nossa Senhora do Monte (IRCP 145, 147, 156 e 158). Poderão ser placas (só o saberemos quando se proceder à remoção total do reboco que as envolve) ou paralelepípedos, como o que se expõe no Museu Nacional de Arqueologia (n. ${ }^{\circ} 7096$, IRCP 157).

Aventou D. Fernando de Almeida $(1964,51)$ a hipótese de ter sido Frei Manuel do Cenáculo (1724-1814) o autor ou o promotor dessas cópias «trazidas do Castelho Velho». É bem provável que sim. A vontade de perpetuar no futuro um texto que, por vicissitudes várias, em breve poderia apagar-se de vez levou os académicos e, de um modo geral, os homens de cultura do século XVIII a recopiarem as inscrições legadas pelos Romanos $\left({ }^{(n)}\right.$.

Aqui, o problema em aberto não se prende directamente com a epigrafia romana mas sim com a história cultural de Santiago do Cacém: não haverá nos registos das instituições locais nenhum eco da execução dessas cópias? Terá sido esta uma iniciativa individual como a que se documenta em Cuba - ou duma qualquer instituição?

O citado artigo de José António Falcão pode, na verdade, trazer luz sobre este ponto, na medida em que dá conta do particular interesse de Frei Manuel do Cenáculo por Miróbriga, onde, em Abril de 1793, teria mandado proceder a escavações, organizando outras campanhas em 1801 e 1808 (Falcão 1988, 41-42). É, pois, muito provável que date dessa época a feitura das cópias em apreço. Talvez a documentação do Arquivo Histórico da Real Sociedade Arqueológica Lusitana venha proporcionar, a esse propósito, informação mais pormenorizada.

\section{Esculápio}

A pedra com a atrás referida inscrição ao deus Esculápio já foi cuidadosamente retirada da parede da fachada oriental do Hospital do Espírito Santo. Assim se tornou possível mais adequada salvaguarda de

(n) Idêntico fenómeno se passou em relação a um epitáfio hoje metido numa parede da igreja matriz de Cuba, onde expressamente se escreveu: F(rancisco) J(osé) O(liveira) A(nno) D(omini) / MDCCXXIV (IRCP 334). E, em Bobadela, na célebre inscrição da flaminia Júlia Modesta (CIL II 397), explica-se: «Este letreiro se achou na igreja velha. 1746». 
tão importante monumento, colocando, em seu lugar, uma réplica; por outro lado, maior facilidade haverá em o estudar pormenorizadamente.

Penso que, apesar dessa iniciativa, não irão acabar de imediato as questões assaz polémicas que o texto levanta, desde a leitura e sua tradução até à correcta interpretação do seu conteúdo (vide fotos 1 e 2). $\mathrm{O}$ facto de ser uma ara (com mais de um metro de altura) e não uma placa, como se pensara, atribui-lhe, sem dúvida, um valor acrescentado, porquanto desta sorte se obteve uma confirmação suplementar acerca do culto a Esculápio prestado em santuário próprio (cf. Encarnação 1991, 186 e 1993,316).

Parece, no entanto, insofismável poder deduzir-se do documento que também o deus da Medicina era particularmente venerado em Miróbriga; que muito provavelmente ali haveria um templo (Alarcão 1990, 465), e que, em sua honra, se celebravam solenes festividades anuais a que acorriam peregrinos, como este médico pacense. Igualmente se afigura legítimo supor que as solenidades eram da responsabilidade dos magistrados locais e que, neste caso, Januário teria contribuído para elas com um legado.

Estas hipóteses carecem, porém, de ulteriores confirmações, inclusive mediante o achamento de textos idênticos, aqui ou mesmo noutras partes do mundo romano - porque não é de crer que esta atitude tenha sido tão singular e outras semelhantes se não documentem noutros lugares de culto.

Permita-se-me, conseguintemente, que remeta para uma releitura do que escrevi em 1981 (pp. 27-29) e em 1984 (pp. 218-220 e 792). Concluía em 1981:

«O mau estado da pedra e o facto de estar metida no alto duma parede, dificultando a leitura — impedem, por enquanto, certezas interpretativas. Aliás, o próprio texto é sibilino, sem paralelos conhecidos, prestando-se a forma praestiterit, conjuntivo decerto regido por um quod, a variadas interpretações. [...] Contudo, uma coisa é certa: a eventual presença do vocábulo Quinquatrus, designativo duma festa tradicional em honra de Minerva, divindade que, tendo qualidades médicas, teria aqui cedido o lugar a Esculápio - sugere a existência, em Miróbriga, duma festividade oficial, que (atendendo ao vocábulo deus) poderia muito bem ser a continuação romana duma manifestação religiosa à divindade indígena com que Esculápio se teria identificado. Terá Miróbriga funcionado desde tempos imemoriais como local de peregrinação, com um santuário e outros edifícios públicos (há as termas, o circo...), 
onde o «Esculápio» indígena e, depois, o «Esculápio» romano, anualmente se festejava por causa das curas milagrosas operadas? Se a resposta for afirmativa - e talvez o prosseguimento das escavações um dia no-lo documente - teríamos aqui a confirmação dum culto pré-romano que, através da interpretatio, continuava ao tempo dos Romanos com todos os foros de oficial.

A inscrição é, pois, muito importante: todos não seremos de mais para correctamente a interpretarmos» (pp. 28-29) (12).

E, em comentário à minha interpretação de 1984 (IRCP 144), o doutor Francisco de Oliveira (1986, 343) escreveu o seguinte:

«Interpreto a expresso OB MERITA SPLENDIDISSIMI ORDINIS como explicitação do motivo da homenagem, equivalente, portanto, do habitual OB HONOREM (e. g. IIIIIIVIR(atus), que podemos observar em IRCP 11 e 73, onde também se toma a divindade como outorgante da distinção que motiva a epígrafe. No caso presente, há um agradecimento a Esculápio, que é tomado como responsável pela distinção que consistiu na entrada no splendidissimus ordo, acaso como duúnviro. Em agradecimento, Januário lavra no seu testamento uma estátua a Esculápio, além de (leitura ET em vez de EI) deixar dinheiro com que pagar festas em honra de Minerva, deusa dos artífices e dos médicos (na hipótese da leitura QVINQVATRIVM, ou uma manifestação lúdica, o pentatlo, oferecido à comunidade, se lermos QVINQVERTIVM, ou QVINQVARTIVM, com $t r$ por $r t$.

A última hipótese apoia-se em IRCP 73, onde o beneficiado com o sex virato dedica uma estátua a Fortuna, além de jogos e dádivas ao povo. Em consequência, proponho para a epígrafe a seguinte tradução:

Ao deus Esculápio. Gaio Atio Januário, médico pacense, pelo merecimento de ordem ilustríssima, legou em testemunho (dinheiro) que também pagasse Quinquátrias (ou: um pentatlo)...».

\section{A ara da Cascalheira}

Reveste-se de elevado interesse a tentativa de estudo da ara que um manuscrito da Biblioteca de Évora garante como proveniente da Herdade da Cascalheira, na freguesia de Santo André (Falcão 1988) (13).

$\left({ }^{, 2}\right)$ Embora se trate de uma publicação póstuma, cumpre assinalar que esta inscrição foi referida, de novo, por D. Fernando de Almeida (1988, 24-26). Vide 
Trata-se, de facto, dum bonito exemplar de monumento funerário romano, decorado à maneira clássica, com frontão ornamentado de motivos vegetalistas e toros com rosáceas nos topos $\left({ }^{*}{ }^{*}\right)$. O campo epigráfico em forma de portal, terminado superiormente em semicírculo, faz lembrar outros monumentos da região. Compare-se, por exemplo, com IRCP 336, achado em S. Margarida do Sado, no vizinho concelho de Ferreira do Alentejo: embora já não disponha de capitel, apresenta inclusive dimensões equivalentes 112 x 57,5/67,5 $\mathrm{x}$ 28,5/44,5 (i5).

E assaz plausível a ideia, sugerida pelos autores, de que o documento tabeliónico se destinava a ser presente «a uma instância de carácter público», possivelmente a Academia Real da História Portuguesa, atendendo à sua "ampla actividade compilatoria de fontes arqueológicas, de modo a servirem de subsídios para as investigações dos seus membros sobre história eclesiástica e secular» (ibidem, p. 41).

Pela tipologia e pela presença de consagração aos deuses Manes, o monumento datará muito provavelmente do século II da nossa era. E sou da mesma opinião dos autores: o copista pouco ou nada sabia de inscrições romanas e, enquanto se não reencontrar a $\operatorname{ara}\left({ }^{16}\right)$, não vale a

também RémY 1991 324-326. No II Colóquio Internacional de Epigrafia «Divindades Indígenas e Interpretado Romana» (Sintra, 16-18.03.1995), Vasco Mantas apresentou uma comunicação intitulada «O culto de Esculápio no Sul da Lusitânia: uma forma de interpretatio?», em que também advogou uma estreita relação entre este Esculápio e uma divindade pré-romana de funções idênticas.

$\left.{ }^{13}\right)$ Designo doravante por autores os quatro subscritores desse estudo.

(,4) Os «motivos» existentes sob o campo epigráfico não se me afiguram providos de significado preciso. Inclino-me a ver aí não desenhos de qualquer coisa mas, de preferência, a representação de concavidades resultantes da erosão ou dos maus tratos sofridos pelo monumento, uma vez que é de todo inusitada a presença de relevos decorativos nesse espaço. Também me parece que a peça está representada na totalidade (capitel, fuste e base): as linhas paralelas inferiores correspondem a molduração da base, a que se seguiria a habitual faixa reversa.

$\left.C^{5}\right)$ O documento diz que a pedra tinha 7 palmos de altura total $(\sim 154 \mathrm{~cm}), 2$ palmos e 4 dedos de largura $(\sim 52 \mathrm{~cm})$ e um palmo e 4 dedos de espessura $(\sim 30 \mathrm{~cm})$. Certamente por gralha, os autores indicam $62 \mathrm{~cm}$ de altura e apenas 4 dedos de grossura.

${ }^{(16)} \quad$ Por aquilo que conheço do espólio epigráfico dos museus de Évora e de Beja bem como dos álbuns de Frei Manuel do Cenáculo, não creio que a peça alguma vez tenha feito parte da sua colecção. Também não me parece que alguém a haja transportado para o Museu Nacional de Arqueologia. Por conseguinte, o mais certo é ter sido reutilizada nalguma construção das imediações da propriedade onde foi 
pena matar a cabeça com hipóteses de invenção dum texto aceitável, a partir do transmitido. Há, todavia, dois ou três pontos que se poderão assinalar.

Reza o documento que os caracteres «foram facilmente copiados» e que «aonde vão os pontos eram alguns caracteres que já estavam apagados por causa do tempo em que o padrão foi trazido para o dito moinho de alguma distância dele, aonde se achou enterrado» (ibidem, p. 48). Quer isto dizer que ao leitor de então as letras visíveis não terão oferecido dúvida. Podemos, consequentemente, deduzir a partir daí algumas conclusões.

Em primeiro lugar, a menção da idade estará correcta: $\mathrm{AN}$ (norum) XVIIII (undeviginti), 'de dezanove anos'.

$\mathrm{Na}$ última linha, além da fórmula $\mathrm{P}$ (onendum) - ou $\mathrm{F}$ (aciendum) - C(uravit), estará a usual indicação $\mathrm{H}(/ \mathrm{c}) \mathrm{S}$ (itus) $\quad E($ st) $\mathrm{S}($ it) $\mathrm{T}$ (ibi) Tierra) L(evis), na medida em que ainda eram visíveis as hastes verticais do $\mathrm{H}$.

Raciocinaram bem os autores quando pensaram que o nome do defunto estaria em genitivo por terminar (verosimilmente) em I. Embora não seja muito usual na época a que o monumento remonta, aceita-se a hipótese. Também é viável que o $\mathrm{O}$ inicial seja má leitura da sigla do praenomen $Q$ (uintus). O defunto seria, por conseguinte, do sexo masculino e deteria, muito possivelmente, os tria nomina. $\mathrm{O}$ único gentilicio começado por MV documentado na área é Mummius (IRCP 331-333 e 336); concordamos com os autores quando manifestam certa perplexidade em reconstituir aí Murricius ( ${ }^{17}$ ), não atestado na Península Ibérica. A seguir a Mur(r)ici poderá vir a filiação ( $\left.{ }^{18}\right)$ e, quiçá, a indicação da tribo: A (uli) F (ilii) CA[L ](eria tribu), interpretando-se como F o I da transcrição (só a barra vertical estaria visível). Haveria lugar para mais uma letra no final (o espaço em branco assim no-lo

identificada a 6 de Dezembro de 1724. Uma pesquisa no eventual espólio dos descendentes do capitão António Dias Borralho também poderá trazer alguma pista de interesse.

(17) No texto (p. 45) vem, certamente por lapso, Murricus. O gentilicio atestado é Murricius, Murrício (SCHUlze, 1966, 196 e 428; Solin 1988, 123); de cognomes com idêntico radical (?) teñamos Muricel(l)us, Muricillus, Muricinus, Muriclio, Muric(u)lus e Muricus (Solin 1988, 365).

(18) Se se procurar seguir o texto transcrito e como o A tem sentido, não vejo motivo para aí se 1er M de $\mathrm{M}$ (arei). 
permite deduzir), além do L: seria, talvez, o começo do cognomen: o proposto Anioni (por Anniani) é plausível.

Nas linhas 5 e 6, estará a identificação da dedicante, deveras difícil de discernir. O poderá ser, de novo, $\mathrm{Q}$ mal lido, porque a junção $\mathrm{AO}$ seria estranha naquela posição; por isso as sílabas NICA inclinam-nos a ver aí a terminação dum antroponimo feminino; por outro lado, o $\mathrm{C}$ antes do $\mathrm{N}$ corresponderá verosimilmente a $\mathrm{O}$. Acontece, porém, que, entre os antropónimos conhecidos terminados em - ONICA ou ONICVS (Solin, 429 e 446) não figura nenhum semelhante a ARONICA $\left({ }^{19}\right)$. Se o O seguinte estivesse por $\mathrm{Q}$ (uinti), veríamos em MAH a palavra MATER, mas ficaríamos sem solução para a palavra da linha 5. De qualquer modo, parece verosímil que a ara tenha sido mandada lavrar pela mãe do jovem e que, na linha 5, esteja explicitado o laço de parentesco, acompanhado, eventualmente, dum superlativo.

Teríamos, portanto:

$\mathrm{D}$ (is) $\mathrm{M}$ (anibus) $\mathrm{S}$ (acrum) / $\mathrm{Q}$ (uinti) $\mathrm{MVR}<\mathrm{R}>\mathrm{ICI}(/) \mathrm{A}$ (uli) $\mathrm{F}(/ / /) \mathrm{CA}[\mathrm{L}]$ (eria tribu) [A?]/NIANI AN(norum) XVIIII (undeviginti) /ARONICA [?] Q(uinti) MAH [?] /NA [?...] / P(onendum) [vel $F($ aciendum) $] \cdot C$ (uravit) $-\mathrm{H}$ (ic) $\bullet[\mathrm{S}$ (itus) $-\mathrm{E}(5 \mathrm{t}) \cdot \mathrm{S}$ (it) $-T$ (ibi) $\bullet$ $\mathrm{T}($ erra) $\bullet \mathrm{L}($ evis $)]$.

Ou seja:

Consagrada aos deuses Manes de Quinto Murrício Aniano, filho de Aulo, da tribo Galéria, de dezanove anos. Arónica (?)(...) mandou fazer (ou colocar). Aqui jaz. Que a terra te seja leve.

Mas, como muito bem frisam os autores (ibidem, p. 45), a interpretação não pode deixar de ser apresentada sob fortes reservas que só a descoberta do próprio monumento logrará talvez dissipar.

\section{IRCP 153}

Tive ensejo de observar, a 9 de Abril de 1992, a estela de que só obtivera conhecimento através da comunicação (inédita) de Santos Barreto e dementino Amaro (1980). Encontrava-se, então, no Clube

(19) O vocábulo LEONICA corresponderia ao número de letras. Arconica, proposto pelos autores, seria, na verdade, caso único.

Conimbriga, 35 (1996) 129-146 
de Património da Escola $\mathrm{C}+\mathrm{S}$ de Alvalade-Sado, identificada sob o n. ${ }^{\circ}$ CONQ.01.4. Podem completar-se e corrigir-se, agora, os dados que publiquei em 1984.

Trata-se, na verdade, de uma estela de topo triangular (não inteiro já, como se pode ver pela foto 3 ), de xisto com pátina acinzentada. Arestas laterais direitas. Campo epigráfico alisado, não delimitado, deteriorado aqui e além pelos sulcos da relha do arado (foto 4).

Dimensões: 68,7 x 44 × 8

MV[N]IA - BROCINA / ARCONIS - F (ilia) - A (nnorum) • $\mathrm{XXXV}$ (quinque et triginta) / $\mathrm{H}(/ \mathrm{cj} \cdot \mathrm{S}$ (ita) $\bullet[\mathrm{E}(\mathrm{V})] \cdot \mathrm{S}($ it) $\bullet T$ (ibi) $\bullet$ $\mathrm{T}($ erra $) \cdot h($ evis $) \cdot$

Aqui Jaz Munia Brocina, filha de Arcão, de trinta e cinco anos. Que a terra te seja leve.

Alt. das letras: 1. 1: 5,5; 1. 2: 4,8/4,2; 1. 3: 4,2. Espaços: 1: (19); 2 e $3: 0,5 ; 4: 34$.

Paginação cuidada - sente-se a presença prévia de linhas de pauta - com alinhamento à esquerda. Pontuação correcta, de pontos circulares bem a meio da linha. Caracteres actuários: $\mathrm{B}$ assimétrico; $\mathrm{R}$ desenhado a partir dum $\mathrm{P}$; $\mathrm{O}$ ovalado; $\mathrm{S}$ vertical e bem simétrico; $\mathrm{T}$ de barras amplas, rectilíneas.

A principal dificuldade de leitura residia no nomen da defunta, particularmente afectado por dois sulcos. Creio, porém, atendendo às dimensões dos outros $\mathrm{NN}$ do texto, que há espaço para um $\mathrm{N}$ antes do $\mathrm{I}$, que se me afigura inteiramente isolado; o $\mathrm{M}$ inicial é claro (de resto, já fora lido como tal pelos primeiros editores).

Teremos, assim, Munia em vez de Aunia. Deste nomen registar-se-ão, na Península Ibérica — dando crédito aos índices do CIL II (p. 1068) e de ILER (p. 723) —, apenas testemunhos (cinco?) com a grafia Munnius. No entanto, a ocorrência de um só $\mathrm{N}$ também se assinalaria em Lisboa, no patronímico Munii (ILER 6376 = CIL II 264); mas a epígrafe carecerá de revisão; noutras paragens do mundo romano não será também frequente, se atendermos à circunstância de os índices de L'Année Epigraphique respeitantes aos anos de 1961 a 1980 (Lassère 1992, 149) somente aduzirem um exemplo garantido: AE 1973604. De origem latina, o gentilicio recebeu, aqui, uma adaptação indígena e, por consequência, devido à forma como vem identificada, Brocina 
deverá incluir-se, portanto, entre as primeiras indígenas romanizadas do ager mirobrigensis.

A paleografia observada, o modo de identificação da defunta e a estrutura textual permitir-nos-ão recuar um pouco a datação anteriormente sugerida: optaria claramente pelos meados do século I da nossa era.

\section{IRCP 173}

No mesmo dia em que vi a epígrafe anterior $\left({ }^{20}\right)$, pude observar estoutra na Casa do Povo de Alvalade-Sado. Trata-se, de facto, de uma esteia muito deteriorada, de que resta um pouco do campo epigráfico, alisado, também ele estragado por efeito de sucessivas passagens da relha aquando dos trabalhos de lavoura (foto 5). Xisto grauváquico com muita pátina. Há um sulco horizontal acima dos primeiros vestígios de letras, que pode marcar o início do campo epigráfico.

Dimensões: $73 \times 36 \times 14$. $\mathrm{H}[?] \cdot \mathrm{S} *$

$[\ldots] \mathrm{yS}[\ldots] /[\ldots] \bullet \mathrm{F}($ ilius vel - ilia $) \quad[\ldots] /[\ldots] \mathrm{RV}++\mathrm{I}[\ldots] /[\ldots]$

Alt. das letras: 1. 1: 3; 1. 2: 4,3; 1. 3: 4,5 $(+=2,2,1=3) ; 1.4: \mathrm{S}=3,5$. Espaços: 1: 20 até ao sulco, 3,8 do sulco até à 1. 1; 2 e 3: 2: 4: 3; 5: 26,5.

Os caracteres subsistentes denotam uma certa cursividade, mormente o S, que é muito esguio e está muito inclinado para diante; F alongado, de barras curtas; V largo; + poderá ser equivalente a X, como acontece noutras esteias de xisto da mesma época, por exemplo em Reguengos (IRCP 424). Seria de esperar aí, na 1. 3, a menção da idade, sendo $\mathrm{V}$ a sigla de vixit e a haste que se segue ao I o começo do $\mathrm{A}$ de $\mathrm{A}$ (nnosf parece-me, no entanto, que, pelo formato da falha anterior ao $\mathrm{V}$, se deve restituir aí um $\mathrm{R}$.

$\mathrm{Na}$ última linha, seríamos tentados a reconstituir a habitual fórmula $\mathrm{H}$ (ic) $\mathrm{S}$ (itus). Mas, na verdade, com os poucos elementos disponíveis, nada mais se poderá adiantar acerca deste epitáfio, a não ser a sua existência e muito provável datação do século I da nossa era.

${ }^{(20)} \quad$ Agradeço à Dra. Filomena Barata todo o apoio concedido para a concretização, com êxito, desta ida a Alvalade e a Santiago do Cacém.

Conimbriga, 35 (1996) 129-146 
Sirva, por conseguinte, este alinhavar de reflexões para confirmar a certeza de que, em Epigrafia - como em História, como, de resto, em todos os domínios científicos —, o saber não é estático, não é um dado a considerar adquirido duma vez por todas. Tal como o Homem e a Natureza, está em permanente devir. $\mathrm{E}$ as dúvidas de hoje serão certezas amanhã — a gerarem, por seu turno, elas próprias outras dúvidas por esclarecer...

Cascais, 17 de Setembro de 1996

\section{BIBLIOGRAFIA}

AlarCão (Jorge de) (coordenação), Portugal das Origens à Romanização $\left(\mathrm{N} .{ }^{\circ} 1 \mathrm{da}\right.$ Nova História de Portugal). Lisboa, 1990.

Almeida (D. Fernando de), Ruinas de Miróbriga dos Célticos (Santiago do Cacém). Setúbal, 1964.

Almeida (D. Fernando de), «Breve notícia sobre o santuário campestre romano de Miróbriga dos Célticos (Portugal)», Gerion -Anejos I 1988 19-33.

BARATA (Maria Filomena dos Santos), «La ciudad romana de Miróbriga», Revista de Arqueologia, 145 (Maio 1993) 36-47.

Barreto (Manuel Rosivelt Santos) e AMARo (dementino), A "villa" de Conqueiros e seu enquadramento arqueológico, comunicação (inédita) apresentada ao IV Congresso Nacional de Arqueologia (Faro, 1980).

BIERS (William R.), Miróbriga. Investigations at an Iron Age and Roman site in southern Portugal by the University of Missouri - Columbia, 1981-1986. Oxford, 1988.

CASTILlO (Carmen), recensão a IRCP in Emerita 56 (1) 1988 132-134.

CIL II = HÜBNER (Emilio), Corpus Inscriptionum Latinarum, II. Berlim, 1869 e 1892. O número que acompanha as siglas CIL corresponde ao número da inscrição.

Correia (Susana), Roteiros da Arqueologia Portuguesa: 3. Miróbriga, Lisboa, 1990.

ENCARNAÇão (José d'), "A religião romana não-oficial nas colónias e municípios da Lusitânia durante o Alto Império», Memorias de Historia Antigua 51981 19-31.

ENCARNAÇão (José d'), «Aureliano homenageado em Miróbriga», Arqueologia e História, série X, voi. 1/2, tomo 1, 1984-1988, 103-107.

ENCARNAÇÃo (José d'), «Religião e cultura na epigrafia de Liberalitas Iulia (Subsídios para o seu estudo)», Les Villes de Lusitanie Romaine, Paris, 1990, 233-253.

EnCARnaÇão (José d'), recensão a Juana Rodríguez Cortés, Sociedad y Religión Clásica en la Bética Romana, Salamanca, 199: Conimbriga 301991 182-186.

Conimbriga, 35 (1996) 129-146 
EnCARNAÇão (José d'), «No tempo dos Romanos, Sines teve uma estátua do deus Marte», O Distrito de Setúbal 18.08.1992 (p. 12).

ENCARNAÇÃo (José d'), «Arqueologia e Epigrafia: uma complementaridade a potenciar», Trabalhos de Antropologia e Etnologia 33 (1-2) 1993 313-327.

FalCão (José António), Ferreira (Jorge M. Rodrigues), Guerra (Amílcar) e Espírito SANTo (Arnaldo), «Epigrafia romana do concelho de Santiago do Cacém - I: A ara funerária da Herdade da Cascalheira (Santo André)», Anais da Real Sociedade Arqueológica Lusitana, 2. ${ }^{a}$ série, 2, 1988, 37-48.

IRCP = ENCARNaÇão (José d'), Inscrições Romanas do Conventus Pacensis, Coimbra, 1984. «Aditamento», Trabalhos de Arqueologia do Sul 11986 99-109. Quando as siglas IRCP forem seguidas de um número sem vírgula significa que se está a fazer referência ao número da inscrição no catálogo; se houver vírgula, o número refere-se à página.

LASSÈRE (Jean-Marie), Tables Générales de T Année Epigraphique - VIIIe série ( 1961 -1980). Paris, 1992.

OLIVEIRA (Francisco de), recensão a IRCP in Humanitas 37-38 1986 338-344.

RÉMY (Bernard), «Les inscriptions de médecins dans les provinces romaines de la Péninsule Ibérique», Revue des Études Anciennes 931991 (3-4) 321-364.

SCHUlzE (W.), Zur Geschichte Lateinischer Eigennamen. Berlim, 1966.

SOLIN (Heikki) e SALOMIES (Olli), Repertorium nominum gentilium et cognominum Latinorum. Hildesheim, 1988. 


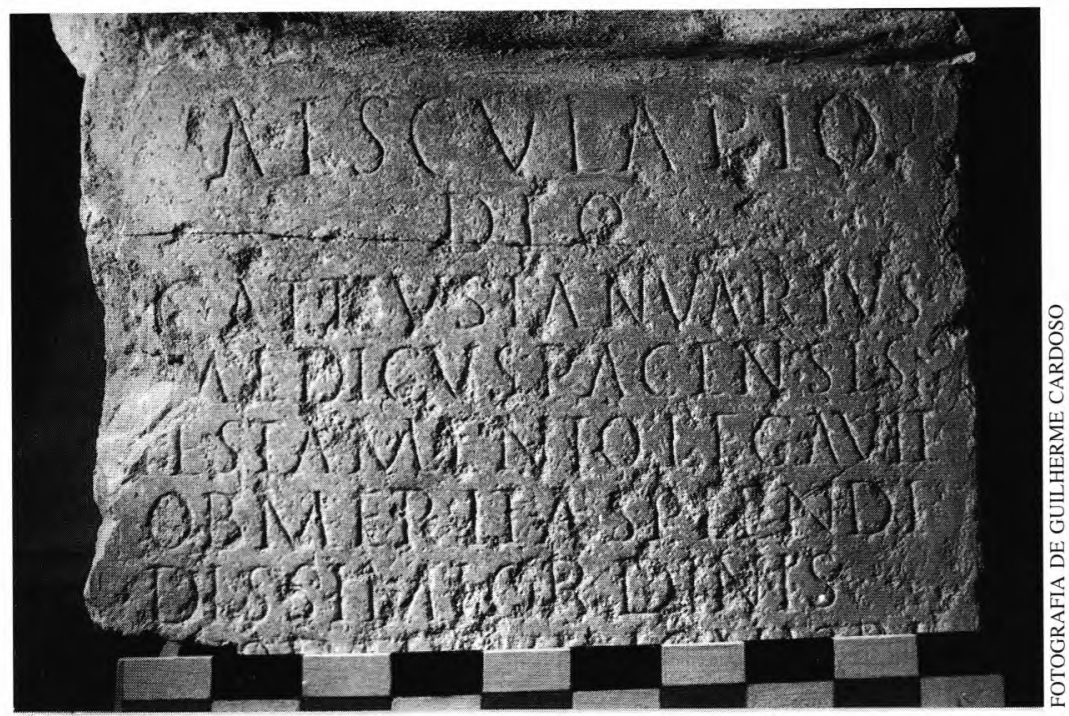

Fото 1 - A metade superior da inscrição a Esculápio.

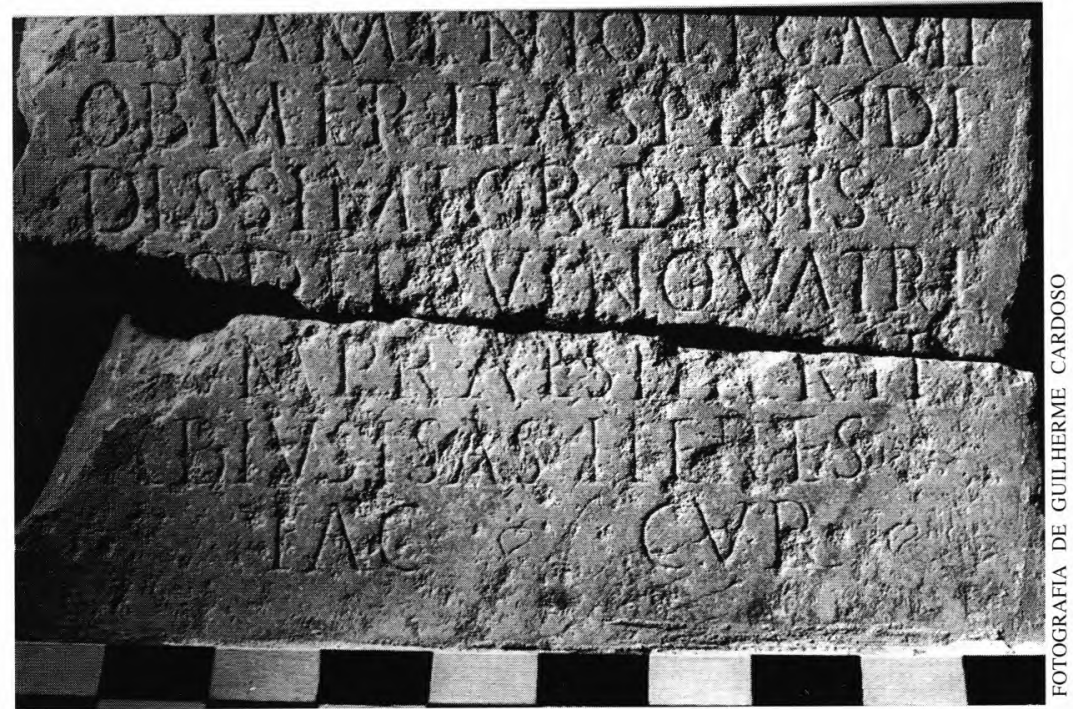

Fото 2 - A parte final da mesma inscrição. 


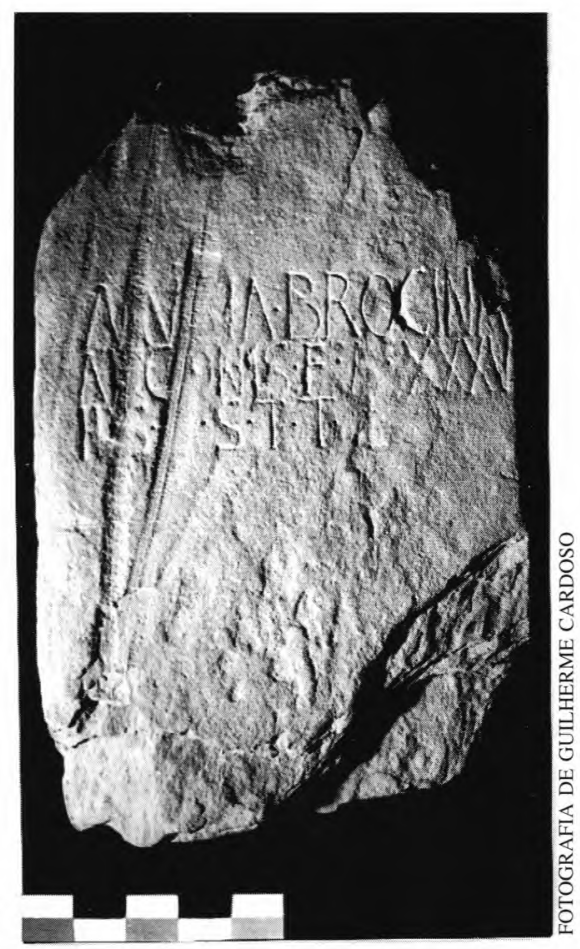

Foто 3 - A estela de Múnia Brocina.

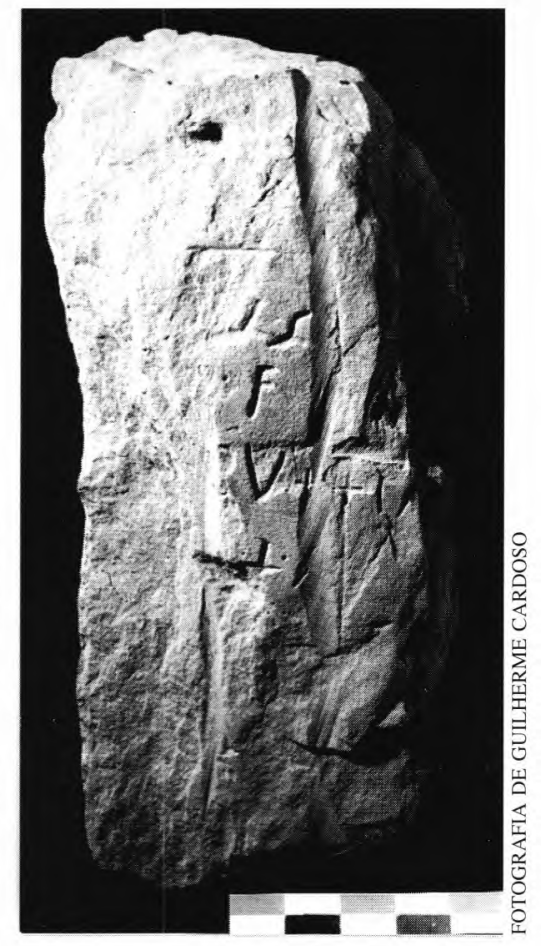

Fото 5 - A segunda estela achada na villa dos Conqueiros

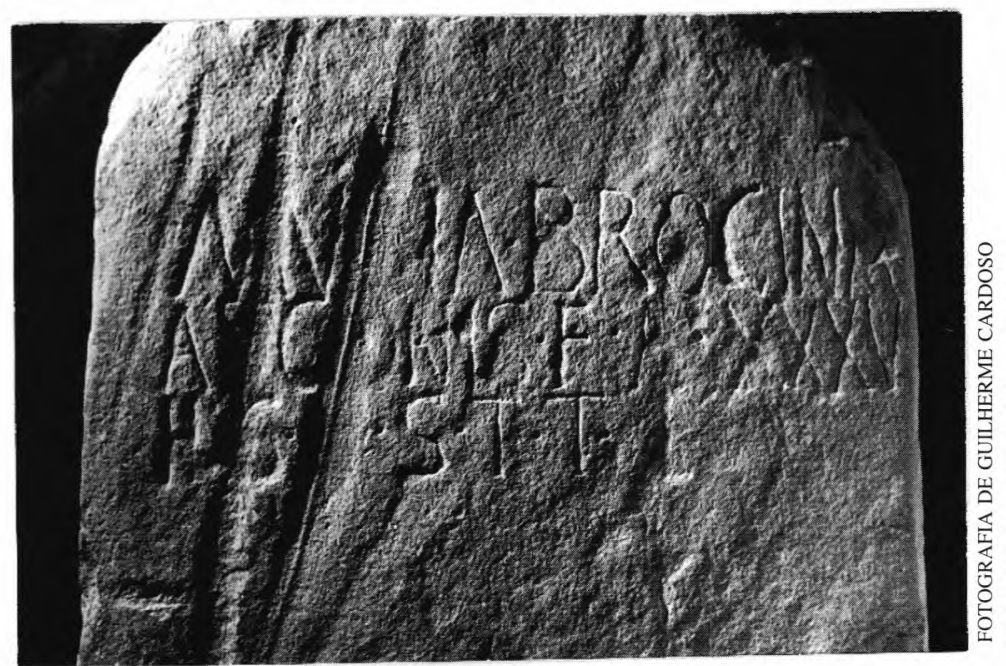

Fото 4 - Pormenor da inscrição do monumento anterior. 